\title{
Doenças e características físico-químicas pós-colheita em pêssego 'Régis' produzido em Presidente Prudente-SP
}

\section{Postharvest diseases and physicochemical characteristics of 'Régis' peach produced in Presidente Prudente-SP}

\author{
Ivan Herman Fischer ${ }^{*}$; Maria Cecília de Arruda $^{2}$; \\ Aparecida Marques de Almeida ${ }^{3}$; Sonia Maria Nalesso Marangoni Montes ${ }^{4}$
}

\begin{abstract}
Resumo
A ocorrência de doenças pós-colheita em pêssegos (Prunus persicae) compromete a qualidade e a quantidade dos frutos colhidos. Neste trabalho objetivou-se caracterizar as podridões e avaliar as características físico-químicas de pêssego 'Régis', produzido em Presidente Prudente-SP. Os frutos foram individualizados e incubados em câmara úmida durante $24 \mathrm{~h}$, permanecendo a $25 \pm 2{ }^{\circ} \mathrm{C}$ e $65 \pm 5 \%$ de UR por mais seis dias. A incidência de podridões foi avaliada após dois e sete dias de armazenamento. Os frutos apresentaram, em média, firmeza de 4,50 Kgf e teores de sólidos solúveis de 11,86 Brix, acidez titulável de $0,56 \%$ de ácido cítrico e 7,08 mg de ácido ascórbico por $100 \mathrm{~g}$ de polpa, 24 h após a colheita. A incidência de podridões fúngicas foi de $16,6 \%$ dois dias após a colheita e 50,3\% após sete dias da colheita. Infestação por moscas-das-frutas atingiu $18,1 \%$ dos frutos. Os principais patógenos encontrados foram Colletotrichum gloeosporioides (22,0\%), Fusicoccum sp. (10,4\%) e Rhizopus stolonifer (6,1\%). As características físico-químicas estudadas não influenciaram na ocorrência das podridões. A elevada incidência de podridões constitui-se na principal causa de danos pós-colheita em pêssego 'Régis' cultivado em Presidente Prudente-SP, evidenciando a necessidade de manejo fitossanitário adequado no campo e na pós-colheita, visando à obtenção de frutos de qualidade comercial satisfatória.
\end{abstract}

Palavras-chave: Prunus persicae, doenças pós-colheita, Colletotrichum

\begin{abstract}
The occurrence of postharvest diseases in peaches (Prunus persicae) compromises the quality and quantity of fruit harvest. The objectives of this paper were to characterize the postharvest diseases and to evaluate the physico-chemical characteristics of 'Régis' peaches grown in Presidente Prudente-SP. Fruits were individualized and kept in a humid chamber for $24 \mathrm{~h}$, and more six days at $25 \pm 2{ }^{\circ} \mathrm{C}$ and $65 \pm 5 \%$ RH. The incidence of rots was assessed after two and seven days of storage. The fruits presented a firmness of $4.50 \mathrm{Kgf}$ on average and soluble solids content of 11.86 Brix, titratable acidity of $0.56 \%$ of citric acid and ascorbic acid of $7.08 \mathrm{mg} .100 \mathrm{~g} \mathrm{~g}^{-1}$ of pulp, $24 \mathrm{~h}$ after harvest. The incidence of fungi rots was $16.6 \%$ two days after harvest, and $50.3 \%$ seven days after harvest. Infestation by fruit flies reached $18.1 \%$ of fruits. The main pathogens detected were Colletotrichum gloeosporioides $(22.0 \%)$,
\end{abstract}

1 Engenheiro Agrônomo, Doutor em Fitossanidade, Agência Paulista de Tecnologia dos Agronegócios/APTA Centro Oeste, Av. Rodrigues Alves, 40-40, 17030-000, Bauru, SP. E-mail: ihfische@apta.sp.gov.br

2 Engenheira Agrônoma, Doutora em Fitotecnia, Agência Paulista de Tecnologia dos Agronegócios/APTA Centro Oeste - Bauru, SP. E-mail: mcarruda@apta.sp.gov.br

3 Engenheira Agrônoma, Doutora em Fitotecnia, Agência Paulista de Tecnologia dos Agronegócios/APTA Centro Oeste - Bauru, SP. E-mail: almeida@apta.sp.gov.br

4 Engenheira Agrônoma, Doutora em Fitotecnia, Agência Paulista de Tecnologia dos Agronegócios/APTA Alta Sorocabana Presidente Prudente, SP. E-mail: soniamontes@apta.sp.gov.br

* Autor para correspondência 
Fusicoccum sp. (10.4\%) and Rhizopus stolonifer (6.1\%). The physico-chemical characteristics evaluated did not influence the occurrence of fungi rots. The high incidence of rots is the main cause of postharvest damages in 'Régis' peach cultivated in Presidente Prudente-SP, evidencing the necessity of a careful phytosanitary procedure in the field and during post harvest stage aiming to produce commercial quality fruits.

Key words: Psidium guajava, storage diseases, Colletotrichum

Os danos pós-colheita em produtos hortícolas podem ser de natureza física, fisiológica e patológica e podem ser notados desde a colheita até o consumidor (SNOWDON, 1990). No Entreposto Terminal de São Paulo (ETSP), os danos ocasionados por doenças pós-colheita de pêssegos [Prunus persicae (L.) Bastch] variaram de 2,4 a 15,2\% dos frutos comercializados nas safras de 2001 e 2002 (MARTINS et al., 2006). No entanto, essa estimativa foi feita em um único ponto da cadeia produtiva o mercado atacadista -, sendo razoável inferir que, ao considerar a totalidade da cadeia produtiva, essas porcentagens possam ser ainda maiores.

A produção de pêssegos no estado de São Paulo, segundo maior produtor brasileiro, superado apenas pelo Rio Grande do Sul, encontra-se em franca expansão, com volume comercializado de 42.949 t em 2.091 hectares de área colhida, em 2005 (AGRINUAL, 2008). Essa situação deveu-se, principalmente, ao desenvolvimento de cultivares, como 'Régis' e 'Biuti', de pouca exigência em frio para a superação da endodormência e adaptadas às condições climáticas da região Sudeste do Brasil (BARBOSA et al., 2003).

Justifica-se, portanto, a caracterização dos danos pós-colheita, com ênfase às doenças, para avaliar a eficiência da produção paulista e facilitar a tomada de decisão por parte do produtor, do atacadista e do varejista, quanto à necessidade de investimento em medidas de prevenção, pois só é possível decidir se a adoção de uma medida de controle será lucrativa ou não, após quantificar os danos causados por determinada anomalia.

As doenças pós-colheita podem ser divididas em duas categorias: (i) as típicas, ocasionadas por patógenos que infectam os frutos após a colheita, frequentemente, por ferimentos; (ii) as quiescentes, ocasionadas por patógenos que infectam o fruto antes da colheita, mesmo na ausência de ferimentos, permanecendo latentes até a maturação fisiológica. Os principais patógenos que causam podridões póscolheita em pêssegos, como Monilinia fructicola e Colletotrichum gloeosporioides, pertencem à categoria de doenças quiescentes, embora patógenos pós-colheita típicos, como os dos gêneros Rhizopus, Cladosporium e Geotrichum também ocorram com importância (MARTINS et al. 2005).

Os objetivos deste trabalho foram caracterizar as doenças pós-colheita e as características físicoquímicas de pêssego 'Régis', produzido em Presidente Prudente-SP.

Foram caracterizados pêssegos 'Régis' de coleção com dez cultivares, idade de seis anos, localizada no campo experimental da APTA Alta Sorocabana, município de Presidente Prudente-SP (coordenadas $22^{\circ} 11^{\prime} \mathrm{S}$ e $51^{\circ} 23^{\prime} \mathrm{W}$, com $424 \mathrm{~m}$ de altitude). A cidade apresenta clima tropical chuvoso e inverno seco, com temperatura e precipitação média mensal, em 2007 , de $23,6^{\circ} \mathrm{C}$ e $104,6 \mathrm{~mm}$, respectivamente (CEPAGRI, 2008). O pomar estudado apresentava 20 plantas de cada cultivar, dez enxertadas sobre o porta-enxerto 'Okinawa', espaçamento 6,0 x 3,0 m, e dez enxertadas sobre 'Umê', espaçamento 6,0 x 1,5 m. O solo do campo experimental é caracterizado como argissolo vermelho, com textura arenosa. O pomar foi irrigado por microaspersão subcopa e o manejo fitossanitário caracterizou-se por pulverizações a cada 21 dias de mancozebe $(0,4 \%)$ alternado com azoxistrobina $(0,02 \%)$, durante a fase vegetativa (agosto a março). Em maio de 2007 foi feita desfolha química com suspensão de $220 \mathrm{~g}$ sulfato de zinco $+120 \mathrm{~g}$ ácido bórico $+240 \mathrm{~g}$ sulfato de cobre +100 L de água. 
Os frutos foram colhidos aleatoriamente nas 20 plantas da cv. Régis. Para a definição do ponto de colheita, utilizou-se como referência a coloração da casca (cor de fundo amarelo-clara), evitandose frutos com defeitos. Foram realizadas cinco amostragens semanais durante os meses de outubro e novembro de 2007, totalizando 361 frutos. Os frutos foram individualizados em bandejas plásticas, transportados ao laboratório da APTA-Bauru e armazenados durante sete dias a $25 \pm 2{ }^{\circ} \mathrm{C}$ e $65 \pm \%$ de UR. Nas primeiras $24 \mathrm{~h}$ de armazenamento, os frutos foram submetidos à câmara úmida visando favorecer a manifestação sintomatológica das doenças em pós-colheita.

A incidência (\%) de doenças foi avaliada após dois e sete dias de armazenamento. Quando havia dúvidas sobre a doença em questão, foram preparadas lâminas com estruturas do patógeno para a identificação sob microscópio óptico e realizado o isolamento do mesmo em meio de cultura batatadextrose-ágar (BDA). Os patógenos encontrados tiveram a patogenicidade confirmada por inoculação em frutos sadios, substituindo-se discos da casca por discos de micélio (3,0 $\mathrm{mm}$ de diâmetro).

Vinte frutos (quatro repetições de cinco frutos) de cada amostragem foram coletados adicionalmente aos da caracterização das doenças e utilizados para a caracterização dos seguintes parâmetros físicoquímicos: a) firmeza da polpa, determinada com penetrômetro marca Bishop FT 327, com ponteira de $8 \mathrm{~mm}$, na região equatorial, evitando-se a linha de sutura, e expressa em Kgf; b) teor de sólidos solúveis, determinado em refratômetro digital marca Atago Palette, modelo PR-101, e expresso em ${ }^{\circ}$ Brix; d) teor de acidez titulável, determinado por titulação com $\mathrm{NaOH} 0,1 \mathrm{~N}$ e expresso \% de ácido cítrico; d) Ácido ascórbico, determinado por titulação com DCFI (2.6 diclorofenol indofenol de sódio) e expresso em mg. $100 \mathrm{~g}^{-1}$ de polpa.

A incidência média dos diferentes patógenos foi submetida à análise de variância e comparada por meio de teste não paramétrico de comparação de múltiplas proporções, ao nível de $5 \%$ de probabilidade (ZAR, 1999). Os resultados obtidos com a caracterização físico-química foram submetidos à análise de variância e as médias comparadas pelo teste de Tukey (5\%). As variáveis físico-químicas foram comparadas entre as amostragens no decorrer da safra (Tukey, $P<0,05$ ) e correlacionadas com a incidência das doenças póscolheita nas amostragens, testando-se correlações simples a 5\% de probabilidade.

Os pêssegos 'Régis' apresentaram incidências de diferentes doenças fúngicas pós-colheita, atingindo contaminação média de 16,6 e 50,3\%, após dois e sete dias de armazenamento, respectivamente (Tabela 1). Essa suscetibilidade às podridões fúngicas é o principal fator limitante para o armazenamento de pêssegos in natura (KARABULUT; BAYKAL, 2002). Vizzotto el al. (2002) também constataram elevada incidência de podridões (20,9-33,0\%) em pêssegos 'Chiripá', após oito dias a $20{ }^{\circ} \mathrm{C}$. Paull (1999) recomenda que a incidência de podridões não deva ultrapassar $30 \%$ durante a vida útil de frutas e hortaliças.

Entre as podridões detectadas em pêssego, a antracnose apresentou a maior incidência média $(22,0 \%)$, diferindo significativamente das demais doenças aofinaldo armazenamento. Segundo Martins et al. (2005), em anos com primavera chuvosa e altas temperaturas, a antracnose pode causar prejuízos consideráveis. As lesões nos frutos são circulares, de coloração marrom castanha, levemente deprimidas e firmes ao toque. As podridões de Fusicoccum e Rhizopus foram estatisticamente semelhantes, com 10,4 e $6,1 \%$ de incidência, respectivamente, aos sete dias de armazenamento, seguidas pelas podridões de levedura, Cladosporium (Cladosporium herbarum), Fusarium (Fusarium spp.) e podridão parda. Outras doenças constatadas em menores incidências médias $(<0,3 \%)$ foram às podridões de Phomopsis (Phomopsis sp.) e Alternaria (Alternaria alternata) (Tabela 1). Considerada por muitos autores (MARTINS et al., 2005; MARTINS et al., 2006) como a mais importante doença do pessegueiro 
no Brasil, a podridão parda apresentou-se de Enquanto a doença é favorecida a $25^{\circ} \mathrm{C}$ (MARTINS maneira secundária em Presidente Prudente-SP, et al., 2005) a cidade apresentou temperatura possivelmente, em função das condições climáticas máxima mensal, de setembro a novembro, de desfavoráveis, especialmente, as altas temperaturas. $\quad 32,8{ }^{\circ} \mathrm{C}$ (CEPAGRI, 2008).

Tabela 1. Incidência (\%)* de doenças pós-colheita em pêssego 'Régis' cultivado em Presidente Prudente$\mathrm{SP}$, após dois e sete dias de armazenamento a $25 \pm 2^{\circ} \mathrm{C}$

\begin{tabular}{lcc}
\hline Doenças & \multicolumn{3}{c}{ Armazenamento } \\
\cline { 2 - 3 } & 2 dias & 7 dias \\
\hline Antracnose & $6,1 \mathrm{a}$ & $22,0 \mathrm{a}$ \\
Podridão de Fusicoccum & $1,9 \mathrm{abcd}$ & $10,4 \mathrm{~b}$ \\
Podridão de Rhizopus & $4,1 \mathrm{ab}$ & $6,1 \mathrm{bc}$ \\
Podridão de levedura & $2,7 \mathrm{abc}$ & $3,3 \mathrm{~cd}$ \\
Podridão de Cladosporium & $1,1 \mathrm{bcd}$ & $3,0 \mathrm{~cd}$ \\
Podridão de Fusarium & $0,4 \mathrm{~cd}$ & $2,7 \mathrm{~cd}$ \\
Podridão parda & $0,3 \mathrm{~cd}$ & $2,3 \mathrm{~d}$ \\
Podridão de Phomopsis & $0,0 \mathrm{~d}$ & $0,2 \mathrm{e}$ \\
Podridão de Alternaria & $0,0 \mathrm{~d}$ & $0,2 \mathrm{e}$ \\
\hline Total & 16,6 & 50,3 \\
\hline
\end{tabular}

* Média de cinco colheitas, totalizando 361 frutos.

** Dados seguidos pela mesma letra minúscula na coluna não diferem entre si, ao nível de $5 \%$, pelo teste não paramétrico de comparação de múltiplas proporções (Zar, 1999).

Observou-se elevada infestação de moscas-dasfrutas, com média de 18,1\% dos frutos analisados, possivelmente, influenciada pelo não emprego de inseticidas no pomar. Esses frutos foram desconsiderados na quantificação das doenças pós-colheita, pois os frutos atacados pelas larvas ficam imprestáveis para o consumo e amadurecem precocemente.

Os índices de perdas de frutos pós-colheita são geralmente reflexos dos percentuais de incidência das doenças nessa fase, uma vez, que os frutos são desqualificados para a comercialização pela simples presença dos sintomas. A grande incidência e diversidade de doenças constatada neste estudo sugerem a necessidade do emprego de medidas de controle mais efetivas durante as fases de produção e pós-colheita de pêssego, visando propiciar a redução dessas perdas.
As características físico-químicas firmeza de polpa, sólidos solúveis, acidez titulável e ácido ascórbico em pêssego 'Régis' e as correlações com o total de podridões estão expressos nas Tabelas 2. Foram observadas variações significativas das características físico-químicas entre as amostras de pêssego, no entanto, não influenciaram no total de podridões.

Os dados da firmeza de polpa do pêssego 'Régis' (Tabela 2) revelaram-se, em média, um pouco mais elevados que o observado na mesma cultivar em Jaboticabal-SP (MAYER; MATTIUZ; PEREIRA, 2008). Pêssegos com omesocarpoamarelo, a exemplo do 'Régis', são preferidos para a industrialização, pois apresentam textura mais firme e conservam a forma após o cozimento. Para o consumo in natura, na Califórnia/EUA, os consumidores rejeitam frutos muito moles, com firmeza de polpa inferior a $2 \mathrm{Kgf}$ (CRISOSTO; MITCHELL; JOHNSON, 1995). 
Tabela 2. Características físico-químicas de pêssego 'Régis' produzido em Presidente Prudente-SP, 24 h após a colheita semanal

\begin{tabular}{ccccc}
\hline \multirow{2}{*}{ Colheita } & \multicolumn{4}{c}{ Variáveis } \\
\cline { 2 - 5 } & $\begin{array}{c}\text { Firmeza } \\
(\text { Kgf })\end{array}$ & $\begin{array}{c}\text { Sólidos solúveis } \\
\left({ }^{\circ} \text { Brix }\right)\end{array}$ & $\begin{array}{c}\text { Acidez titulável } \\
\text { \% acido cítrico })\end{array}$ & $\begin{array}{c}\text { Ácido ascórbico } \\
(\text { mg vitamina C/100g })\end{array}$ \\
\hline $24 / 10 / 2008$ & $4,52 \mathrm{ab}$ & $11,87 \mathrm{ab}$ & $0,60 \mathrm{a}$ & $10,61 \mathrm{a}^{2}$ \\
$31 / 10 / 2008$ & $3,41 \mathrm{~b}$ & $11,26 \mathrm{~b}$ & $0,50 \mathrm{~b}$ & $7,29 \mathrm{~b}$ \\
$7 / 11 / 2008$ & $4,71 \mathrm{ab}$ & $10,83 \mathrm{~b}$ & $0,51 \mathrm{~b}$ & $4,65 \mathrm{c}$ \\
$14 / 11 / 2008$ & $4,50 \mathrm{ab}$ & $11,85 \mathrm{ab}$ & $0,55 \mathrm{ab}$ & $6,96 \mathrm{bc}$ \\
$21 / 11 / 2008$ & $5,38 \mathrm{a}$ & $13,47 \mathrm{a}$ & $0,62 \mathrm{a}$ & $5,88 \mathrm{c}$ \\
\hline $\mathrm{CV}(\%)$ & 19,60 & 8,15 & 6,78 & 9,07 \\
$\mathrm{r}(\mathrm{p}<0,05)^{1}$ & $-0,51$ & $-0,12$ & $-0,59$ & $-0,51$ \\
\hline
\end{tabular}

${ }^{1}$ Coeficientes de correlação entre os parâmetros físico-químicos e a incidência total de podridões.

${ }^{2}$ Dados seguidos pela mesma letra minúscula na coluna não diferem entre si, ao nível de $5 \%$, pelo teste de Tukey.

Os valores de sólidos solúveis e acidez titulável obtidos no presente estudo, com médias de 11,86 Brix e $0,56 \%$ de ácido cítrico, respectivamente, foram semelhantes aos observados em JaboticabalSP (MAYER; MATTIUZ; PEREIRA, 2008). Entretanto, nas condições climáticas de Jundiaí-SP, os teores de sólidos solúveis foram próximos de 14 ${ }^{\circ}$ Brix (OJIMA et al., 1991). O conteúdo de sólidos solúveis aumenta conforme o desenvolvimento do fruto e varia de acordo com a cultivar, a região, a safra, o manejo do pomar e a localização do fruto na planta, o que exige combinação com outros métodos, quando utilizados para a determinação do índice de colheita (CRISOSTO; MITCHELL; JOHNSON, 1995). Por sua vez, em geral, a acidez titulável diminui com o amadurecimento e varia entre as cultivares, contudo, as variações devidas às diferenças climáticas da região e do ano são menores do que as que ocorrem com o conteúdo de sólidos solúveis (CRISOSTO; MITCHELL; JOHNSON, 1995). Segundo Ojima et al. (1991), os frutos de 'Regis' possuem equilíbrio nos teores de açúcares e de acidez, e constituem-se como opção interessante á persicultura do estado de São Paulo, por ter dupla finalidade e maturação precoce.

Os valores de ácido ascórbico variaram entre 4,7 a 10,1 mg por $100 \mathrm{~g}$ de polpa, entre as amostras (Tabela 2). Gil et al. (2002) também verificaram teores de ácido ascórbico entre 3,6 a 12,6, em cultivares de polpa branca e amarela na Califórnia.

Embora associações entre o aumento das infecções com a elevação da concentração de sólidos solúveis ou a diminuição da acidez e / ou da firmeza de polpa tenham sido relatadas em frutos de cereja (NORTHOVER; BIGGS, 1990) e maçã (SHARMA; KAUL, 1988), essas características não auxiliaram no entendimento das causas de resistência/ suscetibilidade dos frutos de pêssego 'Régis', devendo ser consideradas apenas no planejamento da colheita. Fatores como a densidade de inóculo, manejo fitossanitário, nutrição da planta, estado fisiológico do fruto e a interação desses fatores com a temperatura e umidade relativa podem influenciar a incidência de uma doença particular em uma determinada época do ano.

Nas condições experimentais adotadas, foi possível concluir que: 1) a elevada incidência de podridões, especialmente a antracnose e a infestação por moscas-das-frutas, constituem-se nas principais causas de danos pós-colheita em pêssego 'Régis' em Presidente Prudente-SP, evidenciando a necessidade de manejo fitossanitário adequado no campo e na pós-colheita, visando a obtenção de frutos de qualidade comercial satisfatória; 2) As características físico-químicas firmeza de polpa, 
sólidos solúveis, acidez titulável e ácido ascórbico dos frutos não auxiliaram no entendimento das causas de resistência/suscetibilidade dos pêssegos às podridões.

\section{Referências}

BARBOSA, W.; POMMER, C. V.; RIBEIRO, M. D.; VEIGA, R. F.; COSTA, A. A. Distribuição geográfica e diversidade varietal de frutíferas e nozes de clima temperado no Estado de São Paulo. Revista Brasileira de Fruticultura, Jaboticabal, v. 25, n. 2, p. 341-344, 2003.

CEPAGRI - Centro de Pesquisas Meteorológicas e Climáticas Aplicadas a Agricultura. Clima dos Municípios Paulistas. 2008. Disponível em: <http://www.cpa. unicamp.br/outras-informacoes/clima-dos-municipiospaulistas.html>. Acesso em: 10 set. 2008.

CRISOSTO, C. H.; MITCHELL, F. G.; JOHNSON, S. Factors in fresh market stone fruit quality. Central Valley Postharvest Newsletter, Parlier, v. 6, n. 1, p. 17-21, 1995.

AGRINUAL - Anuário Estatístico de Agricultura Brasileira. São Paulo: FNP Consultoria e Comércio. 2008. p. 428-434.

GIL, M. I.; TOMÄS-BARBERÄN, F. A.; HESSPIERCE, B.; KADER, A. A. Antioxidant capacities, phenolic compounds, carotenoids, and vitamin $\mathrm{C}$ contents of nectarine, peach, and plum cultivars from California. Journal of Agriculture and Food Chemistry, Washington, v. 50, n. 17, p. 4976-4982, 2002.

KARABULUT, O. A.; BAYKAL, N. Evaluation of the use of microwave power for the control of postharvest diseases of peaches. Postharvest Biology and Technology, Amsterdam, v. 26, n. 2, p. 237-240, 2002.

MARTINS, M. C.; BETTI, J. A.; LEITE, R. M. V. B. C.; LEITE JUNIOR, R. P.; AMORIM, L. Doenças das rosáceas de caroço. In: KIMATI, H.; AMORIM, L.; REZENDE, J. A. M.; BERGAMIN FILHO, A.;
CAMARGO, L. E. A. Manual de fitopatologia: doenças das plantas cultivadas. 4. ed. São Paulo: Ceres, 2005, v. 2, cap. 62, p. 545-557.

MARTINS, M. C.; LOURENÇO, S. A.; GUTIERREZ, A. S. D.; JACOMINO, A. P.; AMORIM, L. Quantificação de danos pós-colheita em pêssegos no mercado atacadista de São Paulo. Fitopatologia Brasileira, Lavras, v. 31, n. 1, p. 5-10, 2006.

MAYER, N. A.; MATTIUZ, B. H.; PEREIRA, F. M. Qualidade pós-colheita de pêssegos de cultivares e seleções produzidos na microrregião de Jaboticabal-SP. Revista Brasileira de Fruticultura, Jaboticabal, v. 30, n. 3, p. 616-621, 2008.

NORTHOVER, J.; BIGGS, A. R. Susceptibility of immature and mature sweet and sour cherries to Monilinia fructicola. Plant Disease, Saint Paul, v. 74, n. 4, p. 280284, 1990.

OJIMA, M.; CAMPO, F. A.; BARBOSA, W.; MARTINS, F. P.; CASTRO, J. L.; SANTOS, R. R.; SABINO, J. C.; BOVI, V.; RIGITANO, O. 'Régis' - nova cultivar de pêssego para mesa e conserva. Revista Brasileira de Fruticultura, Jaboticabal, v. 13, n. 3, p. 293-296, 1991.

PAULL, R. E. Effects of temperature and relative humidity on fresh commodity quality. Postharvest Biology \& Technology, Amsterdam, v. 15, n. 3, p. 263277, 1999.

SHARMA, R. L.; KAUL, J. L. Susceptibility of apples to brown rot in relation to quantitative characters. Indian Phytopathology, Nova Delhi, v. 43, n. 1, p. 113-115, 1988.

SNOWDON, A. L. A colour atlas of postharvest diseases and disorders of fruit and vegetables. Boca Raton: CRC Press, 1990. 302 p.

VIZZOTTO, M.; ANTUNES, P. L.; BRACKMANN, A.; DALBOSCO, V. Aplicação de cálcio em pré-colheita na conservação de pêssego [Prunus persica (L.) Batsch.], cv. Chiripá. Revista Brasileira de Agrociência, Pelotas, v. 8, n. 1, p. 31-35, 2002.

ZAR, J. H. Biostatistical analyis. New Jersey: PrenticeHall, 1999. 663 p. 